\title{
EDITORIAL
}

\section{The missing link: what mediates the relationship between religiosity and alcohol use?}

\author{
Letícia Oliveira Alminhana, Miguel Farias \\ Wolfson College, University of Oxford, Oxford, England.
}

There is a growing literature on the relationship between religiosity and health (for reviews, see Koenig et al. ${ }^{1,2}$ ), including its impact on alcohol use. .,4 $^{3}$ The vast majority of studies report a negative association between religiosity and alcohol use but, until recently, no data were available for the Brazilian context. Fortunately, this has now been changed with a nationwide study by Lucchetti et al. ${ }^{3}$ which, like U.S. based research before it, showed that individuals with higher levels of religiosity support more restrictive alcohol polices and report less alcohol abuse. ${ }^{3}$ With these results at hand, there is now a need to move further and ask: what are the psychological mechanisms that mediate this relationship? Is it something about religiosity in itself or should we look elsewhere? In this editorial, we suggest that a look at well-known individual differences described in personality and social-cognition research may shed some light on the missing link mediating religiosity and alcohol abuse.

Sociologists like Durkheim have long suggested that the role of religion is to exercise control over people's behavior. But, in a society where there is no obligation to be religious, those with greater self-control - as reflected in the personality trait of conscientiousness - may find themselves more attracted to religious practice and beliefs, as religious traditions ascribe great value to self-control. ${ }^{5}$ Conscientiousness is negatively associated with use of alcohol, tobacco, and drugs, ${ }^{6}$ and individuals with a combination of the sensitive (sensation-seeking) and pessimistic (harmavoidance) temperament types are particularly susceptible to substance abuse. ${ }^{7}$ If we further consider that personality traits causally precede the motivation towards religious behavior and belief, then the association between higher religiosity and a lower level of alcohol consumption would be explained not by religiosity itself but by particular personality dispositions; in this case, by a high level of conscientiousness and a low level of sensation-seeking and harm avoidance. However, the opposite scenario cannot be fully ruled out: personality traits and temperament are susceptible to change, so it is not impossible that religion's emphasis on self-control and self-regulation strategies ${ }^{5}$ may lead to higher levels of conscientiousness and lower levels of sensation-seeking and harm avoidance.

Let us consider a different mediator - namely, cognitive style. One of the interesting findings of Luchetti et al. ${ }^{3}$ was that religiosity was associated with more restrictive alcohol policies. This, of course, is also true of politically conservative individuals and, despite the association

Correspondence: Letícia Oliveira Alminhana, Wolfson College, University of Oxford, Linton Road, Oxford OX2 6UD, England.

E-mail: leticiaalminhana@gmail.com between religiosity and a variety of positive health outcomes, there is strong evidence linking it with politically conservative and prejudiced attitudes, such as homophobia, authoritarianism, and racism. In a recent study, Johnson et al. $^{7}$ reported that a rigid cognitive style mediated the relationship between religiosity and prejudice. Could this rigid cognitive style shape an attitude of distrust both in homosexuality and in permissive drinking behavior, rather than religious behaviour and belief in itself?

We have suggested two potential variables that may mediate the relationship between religiosity and alcohol use: personality traits and cognitive style. Other relevant variables ought to be considered. Our aim was simply to highlight the necessity to move beyond a descriptive or epidemiological level of research and into a more multilayered one, which actually attempts to explain how these associations occur; in other words, what are the motivational, emotional, cognitive, or behavioral variables, whether specifically linked to religion or not, that provide us with a model of how religion affects the individual.

\section{Acknowledgements}

LOA is supported by a postdoctoral fellowship from the Science without Borders Program, Coordenação de Aperfeiçoamento de Pessoal de Nível Superior (CAPES).

\section{Disclosure}

The authors report no conflicts of interest.

\section{References}

1 Koenig HG, McCullough M, Larson DB. Handbook of religion and health: a century of research reviewed. New York: Oxford University; 2001.

2 Koenig HG, King DE, Carson BE. Handbook of religion and health. 2nd ed. New York: Oxford University; 2010.

3 Lucchetti G, Koenig HG, Pinsky I, Laranjeira R, Vallada H. Religious beliefs and alcohol control policies: a Brazilian nationwide study. Rev Bras Psiquiatr. 2014;36:4-10.

4 Michalak L, Trocki K, Bond J. Religion and alcohol in the US National Alcohol Survey: how important is religion for abstention and drinking? Drug Alcohol Depend. 2007;87:268-80.

5 McCullough ME, Willoughby BL. Religion, self-regulation, and selfcontrol: Associations, explanations, and implications. Psychol Bull. 2009;135:69-93.

6 Svrakić D, Cloninger CR, Svrakić N, Lazić B, Milivojević D, Nastasić $P$. Drug addiction and choice of drugs: temperament and personality as risk factors. Serb J Experiment Clin Res. 2010;11:93-8.

7 Johnson MK, Rowatt WC, Barnard-Brak LM, Patock-Peckham JA, LaBouff JP, Carlisle RD. A mediational analysis of the role of rightwing authoritarianism and religious fundamentalism in the religiosityprejudice link. Pers Individ Dif. 2011;50:851-6. 